\title{
Phenology, Canopy Composition, and Fruit Quality of Yellow Pitaya in Tropical Taiwan
}

\author{
Yi-Lu Jiang, Tzong-Shyan Lin, and Ching-Lung Lee \\ Department of Horticulture and Landscape Architecture, National Taiwan \\ University, No. 1, Sec. 4, Roosevelt Road, Taipei 106, Taiwan (R.O.C.)
}

\author{
Chung-Ruey Yen \\ Department of Plant Industry, National Pingtung University of Science and \\ Technology, Pingtung 912, Taiwan
}

\begin{abstract}
Wen-Ju Yang ${ }^{1}$
Department of Horticulture and Landscape Architecture, National Taiwan University, No. 1, Sec. 4, Roosevelt Road, Taipei 106, Taiwan (R.O.C.)
\end{abstract}

Additional index words. climbing cactus, flower season, flowering shoot, shoot age, sprouting, Selenicereus megalanthus

\begin{abstract}
Yellow pitaya, Selenicereus megalanthus (Schum. ex. Vaupel) Moran, is a potential new fruit in Taiwan. It sprouts mostly in winter and flowers in late spring and fall. In this study, an average of $60 \%$ shoots within canopies flowered. Shoots sprouted in the current winter flowered in fall and produced winter fruits, and shoots sprouted earlier than the current winter flowered in late spring and produced summer fruits. Floral buds on most shoots appeared at the distal end. The weight, pulp percentage, and total soluble solids of winter fruits were significantly higher than those of summer fruits. The number of black seeds was positively correlated with pulp weight $\left(R^{2}=0.87\right)$. The total soluble solids in the core region of winter fruits reached $22.7^{\circ} \mathrm{Brix}$, higher than that in other regions. Future efforts to improve yellow pitaya production in Taiwan include increasing winter fruit production by enhancing growth of the current year's new shoots through proper canopy management and increasing the size of summer fruit by artificial pollination, fruit thinning, and other means.
\end{abstract}

Yellow pitaya [Selenicereus megalanthus (Schum. ex. Vaupel) Moran], a climbing cactus, is native to Central South America and distributed throughout Colombia, Ecuador, Peru, and Bolivia (Anderson, 2001; Mizrahi et al., 1997; Weiss et al., 1995). It is commercially produced in Colombia and Israel for local as well as European and Japanese markets (Mizrahi and Nerd, 1996, 1999; Mizrahi et al., 1997, 2002; Nerd et al., 2002b; Raveh et al., 1993; Weiss et al., 1995). In Israel, yellow pitaya flowers from October to December, and its fruits are harvested from January to mid-May (Nerd and Mizrahi, 1997; Weiss et al., 1994). Fruit development takes 13-14 weeks in fall and 22-23 weeks in winter (Nerd and Mizrahi, 1998; Tel-Zur et al., 2004).

Pitaya is becoming a popular fruit in Taiwan. Most commonly grown varieties belong to either Hylocereus undatus (Haworth) Britt. \& Rose or H. polyrhizus (Weber) Britt. \& Rose; both produce fruits in summer and fall (Hsu, 2004). Strategies such as breeding for winter cultivars and developing methods to regulate flowering seasons are being implemented to produce winter crops. Theoretically, night breaking

Received for publication 28 June 2011. Accepted for publication 20 Sept. 2011

${ }^{1}$ To whom reprint requests should be addressed; e-mailwendy@ntu.edu.tw. by using supplemental light might lead to winter fruit production (Yen and Chang, 1997), but commercial application of such method is not yet practical. Thus, growing yellow pitaya as a new variety for winter fruit production is of interest. Geographically, Taiwan is located between $22^{\circ} \mathrm{N}$ and $25^{\circ} \mathrm{N}, \approx 10^{\circ}$ further south than Israel; thus, the phenology of yellow pitaya is expected to be different from that in Israel.

The effect of shoot age on floral bud formation and on fruit position is an important concern in orchard management. In cactus pears [Opuntia ficus-indica (L.) Miller], 90\% of the floral buds are produced on the center and distal margins of the cladodes (Nieddu and Spano, 1992); and 1-year-old cladodes showed higher fertility than 2 year olds. Removal of spring-flushed cladodes and flowers in May to June can induce secondary flush and delay flowering for 1-2 months (Barbera et al., 1991a, 1991b; Inglese et al., 1994). In $H$. undatus, floral buds mainly emerge at the distal end of the shoot (Hsu, 2004) and current shoots flower either in the early part (May) or in the late part (September) of the flowering season (Jiang, 2005). Knowing the effect of canopy composition, including the age and the areole number of the shoots, on flowering period is important for productive canopy management.

Yellow pitaya is a tetraploid $(2 n=44)$ in which meiosis occurs irregularly at anaphase
I and therefore often results in reduced pollen viability. Low pollen viability causes low seed numbers per fruit even when fruit set is not a problem in self-pollinated flowers (Lichtenzveig et al., 2000). Because the fruit weight and seed number are positively correlated (Dag and Mizrahi, 2005; Weiss et al., 1994), lower seed numbers often means smaller fruits.

The objectives of the study include investigating the flowering phenology and canopy composition of yellow pitaya in subtropical Taiwan. We detailed the relative position where the floral buds emerged on shoots at different ages within the canopy. The fruit size and quality of different seasons were also compared.

\section{Materials and Methods}

Plant materials. Four-year-old yellow pitaya plants (S. megalanthus) were selected from a private orchard in Kaohsiung, Taiwan (lat. $22^{\circ} 56^{\prime} \mathrm{N}$, long. $120^{\circ} 27^{\prime} \mathrm{E}$ ). The average temperature and precipitation data (Fig. 1) were obtained from a nearby station of the Taiwan Central Weather Bureau. All S. megalanthus plants were grafted on $H$. undatus stocks. The original genetic sources of the scion and stock were untraceable. The grower planted the pitaya in Jan. 2001 and used cement pillars with $1.5-\mathrm{m}$ height to support the climbing plants. The pillars were spaced $2 \mathrm{~m}$ between rows and $1.5 \mathrm{~m}$ within rows. Four surrounding plants were tied onto each pillar as one unit. We selected six units (pillars) in a cluster for our observation beginning Jan. 2004. Shoots flushed before Dec. 2003 were classified as noncurrent and those flushed after Dec. 2003 were classified as current. All shoots and areoles on each shoot were numbered and recorded. The field was irrigated with a hose until the soil surface was completely wet every other week. Compound fertilizer No. 43 (15N-6.5P-12.4K2.4Mg; Taiwan Fertilizer Co., Ltd., Taiwan) was applied twice during the flowering season.

Phenology of sprouting and floral bud emergence. The number and location of new shoots, floral buds, and aborted floral buds were recorded at 2-week intervals from 3 Jan. 2004 to 3 Jan. 2005. Shoots flowered more than once during the 1-year period were classified as reflowering. Canopy composition meant the distribution of the shoots with a different number of areoles, i.e., gray structures with hair and spines situated on the ridge of shoots and beneath which the meristems locate. The percentages of shoots with a certain range of areoles were calculated separately at an interval of 15 areoles. The ratio of areoles transformed into floral buds was calculated for shoots containing 1-30, 31-60, 61-90, and more than 90 areoles separately. To examine the flowering position, each shoot was divided into $10 \mathrm{sec}-$ tions, in equal length, from the distal to proximal ends, and sectional flowering percentage was obtained by dividing the number of flowers in each section by the total number of flowers.

Fruit characteristics. Fruits were harvested when the peel turned bright yellow. Summer fruits were harvested on 21 July 2004 and 


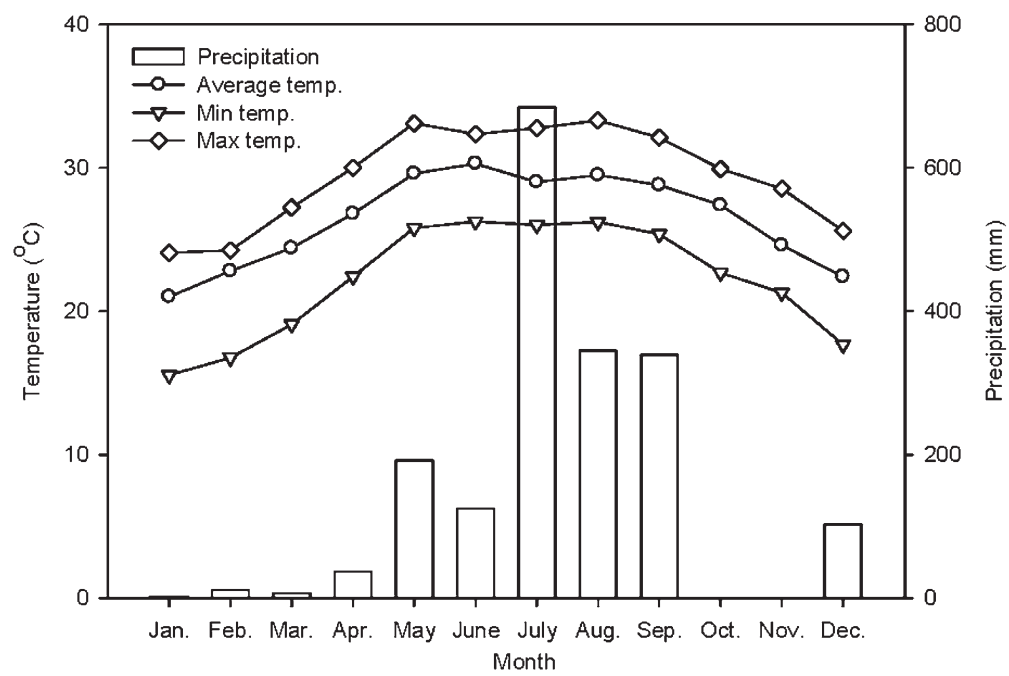

Fig. 1. Average, maximum, and minimum temperature and precipitation in 2004 for Kaohsiung, Taiwan.

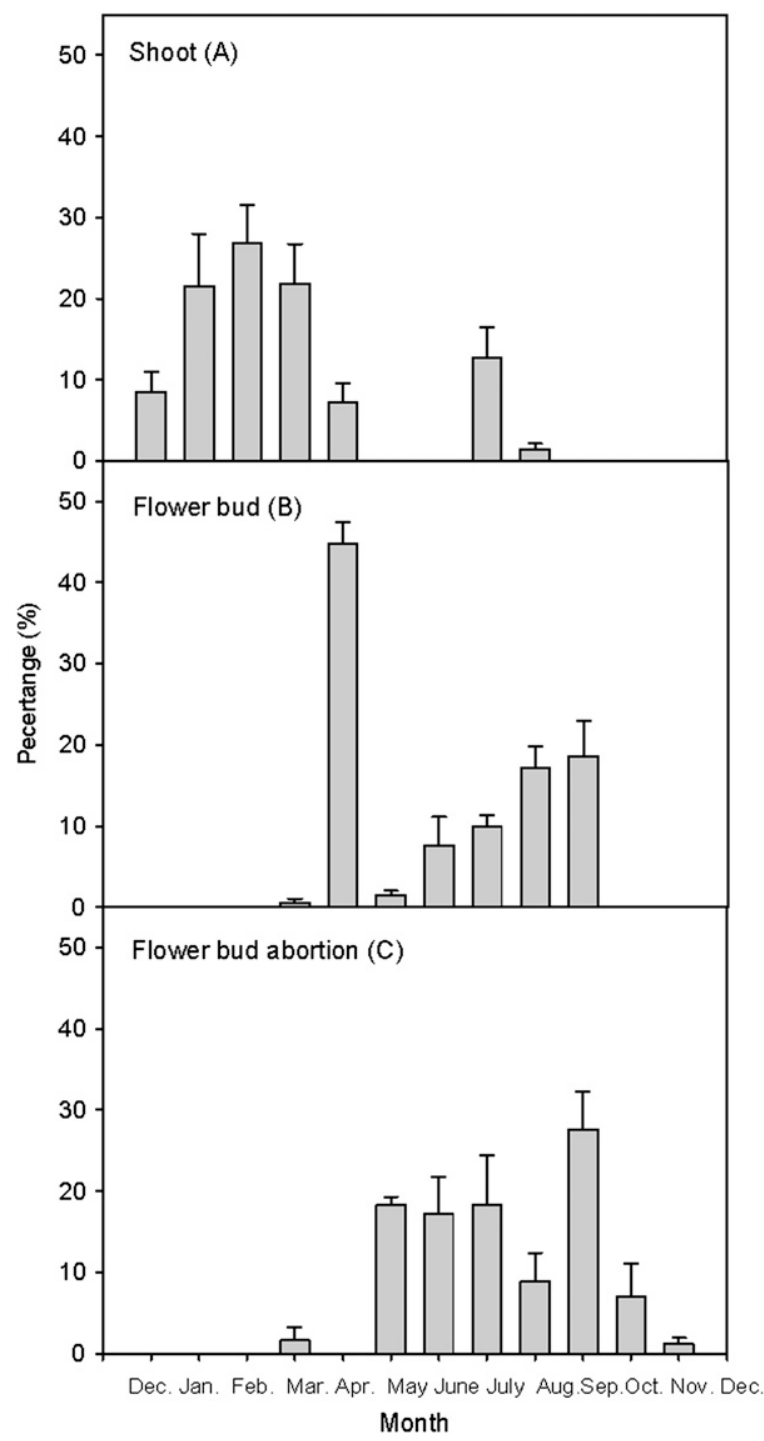

Fig. 2. (A-C) Phenology of sprouting and floral bud formation in S. megalanthus in Taiwan. Data from Dec. 2003 to Dec. 2004 represented as means \pm SE $(n=6)$. Total sprouting rate, floral bud formation rate, and floral bud abortion rate were $100 \%$ within 1 year. winter fruits on 6 Mar. 2005. Fruit length and width, pulp and peel weight, peel thickness at the equator of fruit, number of seeds per fruit, and total soluble solids (TSS) were measured. Fruit index representing fruit shape was obtained by dividing fruit length by width. Seeds were classified as viable (black), aborted (brown), and vestigial (light brown, tiny) categories. Pulp samples from the stylar end, core, stem end, and right and left periphery were taken from halves of 15 vertical cut fruits and measured for TSS using a digital refractometer (PR-101; Atago, Tokyo, Japan).

Data analysis. Data were analyzed with the SAS analysis of variance (SAS Institute Inc., Cary, NC), and pairwise comparisons between treatments were performed using the least significant difference test. The data presented by percentage was transformed by angular or square root before analysis. Data presented were the original untransformed means.

\section{Results}

Phenology of sprouting and floral bud emergence. Sprouting in the yellow pitaya occurred in two waves (Fig. 2A). The major wave occurred between December and April and accounted for $86 \%$ of the yearly sprouting, whereas the minor wave occurred between July and August. Forty-five percent of the yearly floral buds emerged in April, at the end of the major sprouting wave, and the remaining 55\% emerged sluggishly in May through September with an ascending trend (Fig. 2A-B). Thirty percent of the floral buds aborted throughout the flowering season, most severely in September followed by May to July (Fig. 2C). Noncurrent shoots had higher flowering (71.7\%) and reflowering (18.8\%) percentages than current shoots (Table 1). The flowering season began in mid-March and ended at the end of September (Fig. 3). The proportion of current and noncurrent shoots that transformed into flowering shoots varied from month to month. Most noncurrent shoots initiated flowering in late spring and a few of them extended into summer and fall (Fig. 3). Most current shoots initiated flowering in the

Table 1. Percentage of flowering and reflowering shoots and the number of floral buds in current and noncurrent shoots.

\begin{tabular}{lccc}
\hline & $\begin{array}{c}\text { Flowering } \\
\text { shoots } \\
(\%)^{\mathrm{z}}\end{array}$ & $\begin{array}{c}\text { Reflowering } \\
\text { shoots } \\
(\%)^{\mathrm{y}}\end{array}$ & $\begin{array}{c}\text { No. of floral } \\
\text { buds per } \\
\text { flowering } \\
\text { shoot }^{\mathrm{x}}\end{array}$ \\
\hline Noncurrent & 71.7 & 18.8 & 2.0 \\
Current & 46.0 & 1.8 & 1.5 \\
LSD $_{0.05}$ & 10.0 & 10.0 & 0.3 \\
\hline
\end{tabular}

${ }^{\mathrm{z} N u m b e r}$ of flowering shoots/total number of shoots.

${ }^{\mathrm{y}}$ Number of reflowering shoots/total number of shoots. Reflowering means the shoots flowered more than once.

xTotal number of floral buds/total number of flowering shoots.

Analysis of variance in the means of the percentage of flowering shoot and reflowering shoot based on the angular and square root data respectively. $\mathrm{LSD}=$ least significant difference 


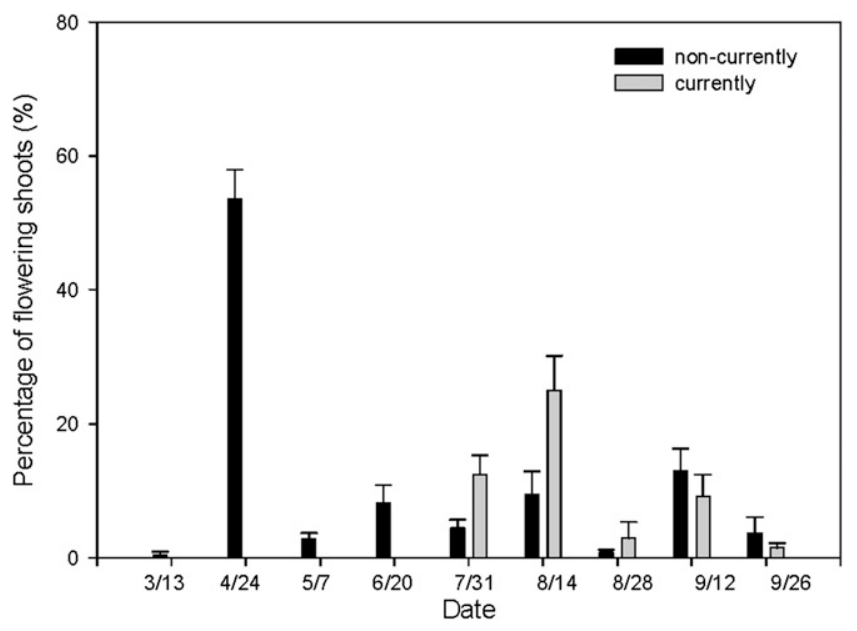

Fig. 3. Monthly transformation of current and noncurrent shoots to flowering shoots in yellow pitaya ( $S$. megalanthus). Data represent the average of 24 plants on six pillars in the flowering season of 2004 Percentage of flowering shoots $=$ number of flowering shoots/total number of shoots .

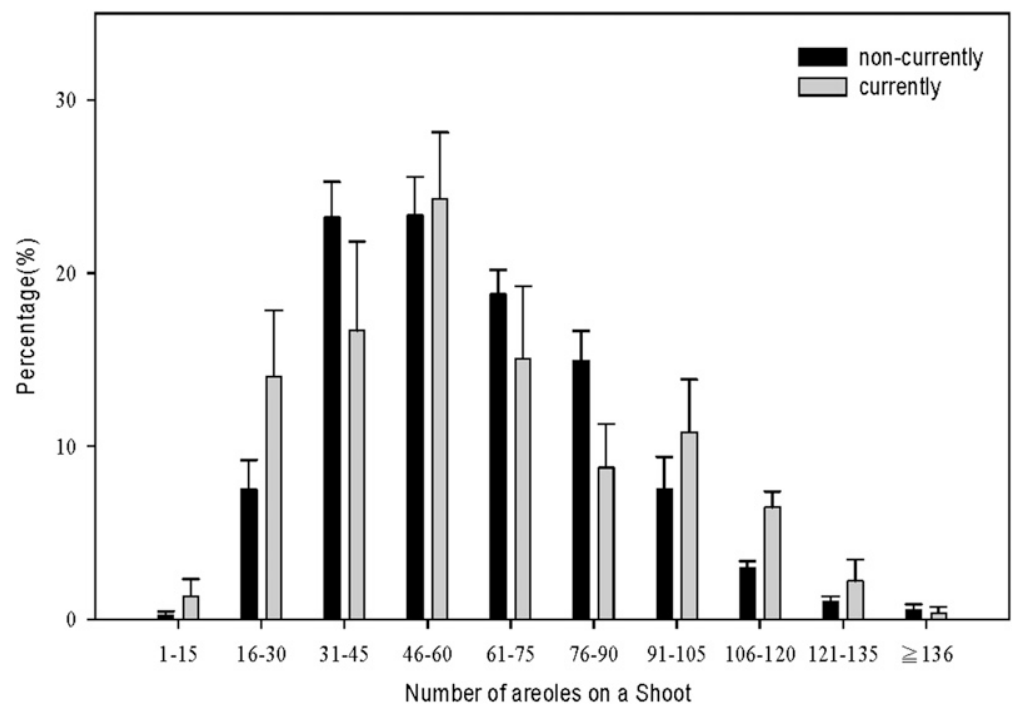

Fig. 4. Canopy composition of yellow pitaya in Taiwan. Data represents the percentage of shoots containing one of 135 areoles in groups of 15 . Noncurrent and current shoots were recorded individually in Dec. $2004(n=6)$. The sums of the percentages of all categories on either current or noncurrent shoots were $100 \%$.

Table 2. Percentage of areoles on current and noncurrent shoots that transformed into floral buds.

\begin{tabular}{lccccc}
\hline & \multicolumn{5}{c}{ Areoles transformed into floral buds (\%) } \\
\cline { 2 - 6 } Type of shoot & $1-30^{\mathrm{z}}$ & $31-60$ & $61-90$ & $\geqq 91$ & LSD $_{0.05}$ \\
\hline Noncurrent & 2.3 & 2.3 & 2.5 & 2.4 & 2.0 \\
Current & 0.2 & 0.6 & 1.2 & 0.9 & 0.7 \\
\hline
\end{tabular}

${ }^{\mathrm{z}}$ Number of areoles per shoot ranged at intervals of 30 .

Analysis of variance in the means of the percentage of areoles transformed into floral buds based on the square root data.

$\mathrm{LSD}=$ least significant difference by row.

summer and early fall (Fig. 3), however. The number of floral buds per flowering shoot was higher in noncurrent shoots than in current shoots (Table 1).

Canopy composition, relative position of floral buds on shoots, and areole transformation ratio. In Jan. 2005, the average number of areoles on noncurrent shoots was 70 per pillar (range, 59-84), whereas that on current shoots was 40 (range, 28-52). When the the floral buds emerged from the last $30 \%$ lengthwise of shoots at the distal end (Fig. 5). On average, $59 \% \pm 6.8 \%$ of shoots in each pillar flowered (data not shown).

Fruit characteristics. Averaged weight of summer fruits was $70.5 \mathrm{~g}$ and that of winter fruits was $175.3 \mathrm{~g}$ (Table 3). Most the summer fruits weighed less than $100 \mathrm{~g}$; and only $4 \%$ of the summer fruits weighed more than $125 \mathrm{~g}$ (Fig. 6). Weights of winter fruits ranged from $25-300 \mathrm{~g}$; and $80 \%$ of the fruits weighed more than $125 \mathrm{~g}$. Summer fruits were characterized by thicker peels and less pulp (Table 3 ). Summer fruits were $16 \%$ less in length and $33 \%$ less in width compared with winter fruits. Therefore, summer fruits had a larger fruit index and were rod-shaped. The percentages of black, brown, and vestigial seeds in summer fruits were $42 \%, 36.8 \%$, and $21.2 \%$, respectively (data not shown in tables); and the number of black seeds correlated strongly with pulp weight $\left(R^{2}=0.87\right)$ (Fig. 7). Total number of black seeds per fruit in winter fruits was twoto three-fold higher than that in summer fruits. TSS in the core and stylar end of a fruit was higher than that in the other parts (Fig. 8).

\section{Discussion}

H. undatus is often used as the stock for propagating pitaya clones for its ease to obtain and acclimation to the environment in Taiwan. Grafted yellow pitaya grows more vigorously than the plant propagated by cutting as a result of a strong root system of $H$. undatus. The phenology of the yellow pitaya propagated by cutting was not different from what we observed in this study (personal observation), however.

In subtropical Taiwan, flowering of yellow pitaya occurred in two waves, a major wave during late spring and a minor wave in early fall. The floral bud initiation period of yellow pitaya overlapped that of $H$. undatus and $H$. polyrhizus (Hsu, 2004). In Israel, yellow pitaya flowers in fall and fruits from January to May with a peak in April (Dag and Mizrahi, 2005; Khaimov and Mizrahi, 2006; Mizrahi and Nerd, 1999; Nerd and Mizrahi, 1998; Weiss et al., 1994), whereas floral bud formation is not often observed in spring. At the beginning of summer, the weather in the Israeli desert is characterized by high light intensity and temperature, and the flowering of climbing cacti is inhibited because plants suffer from such extreme conditions (Nerd et al., 2002a; Raveh et al., 1998). In Taiwan, the weather in late spring favors flowering (Fig. 1) and abundant floral buds emerged in April. The summer in Taiwan is not completely inhibitory for flowering and a minor flowering wave followed (Fig. 2B). The fruit loading on the noncurrent shoots that flowered in the late spring (Fig. 3) might be a probable factor responsible for restricting flowering in May and June. Incidentally, the current shoots during this period were not flowered (Fig. 3).

Floral buds have been reported to emerge simultaneously in April from current and noncurrent shoots in red pitaya (Hsu, 2004). In this study, a majority of yellow pitaya flowers 


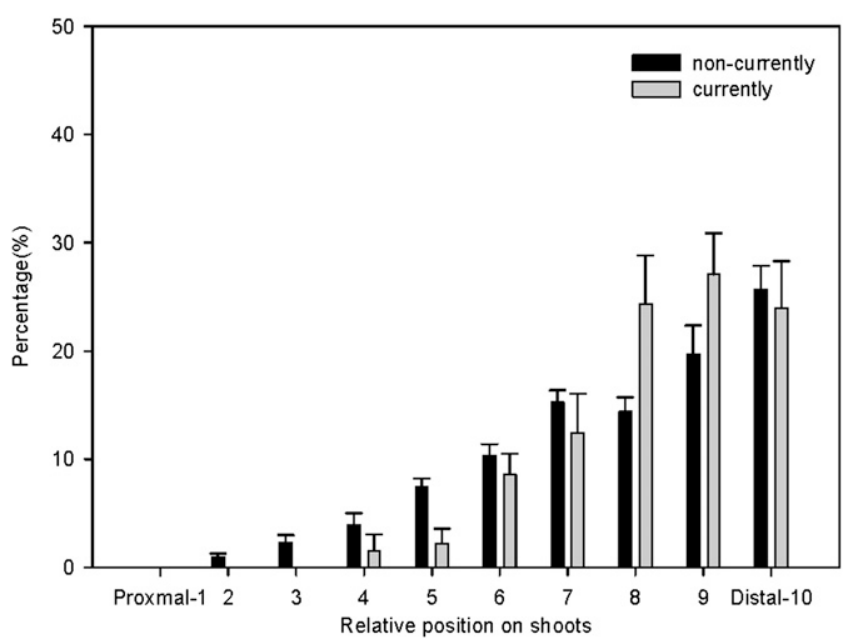

Fig. 5. Position of floral buds generated on yellow pitaya shoots. Data were collected from 24 plants on 373 flowering shoots in Dec. $2004(n=6)$. The sums of the percentages of each section for either current or noncurrent shoots were $100 \%$.

Table 3. Quality of summer and winter fruits of yellow pitaya $(n=187$ for summer fruits and $n=50$ for winter fruits).

\begin{tabular}{|c|c|c|c|c|c|c|c|c|}
\hline & \multicolumn{2}{|c|}{$\mathrm{Wt}(\mathrm{g})$} & \multirow{2}{*}{$\begin{array}{c}\text { Pulp ratio } \\
(\%)\end{array}$} & \multirow{2}{*}{$\begin{array}{l}\text { Peel thickness } \\
(\mathrm{mm})\end{array}$} & \multirow{2}{*}{$\begin{array}{l}\text { Length } \\
(\mathrm{cm})\end{array}$} & \multirow{2}{*}{$\begin{array}{l}\text { Width } \\
\text { (cm) }\end{array}$} & \multirow{2}{*}{$\begin{array}{c}\text { Fruit } \\
\text { index }^{z}\end{array}$} & \multirow{2}{*}{$\begin{array}{c}\text { TSS } \\
\left({ }^{\circ} \text { Brix }\right)\end{array}$} \\
\hline & Fruit & Peel & & & & & & \\
\hline Summer & 70.5 & 35.1 & 48.0 & 3.2 & 8.0 & 3.9 & 2.1 & 19.6 \\
\hline Winter & 175.3 & 61.0 & 61.2 & 2.7 & 9.5 & 5.8 & 1.7 & 20.8 \\
\hline$\underline{\mathrm{LSD}_{0.05}}$ & 12.0 & 4.1 & 3.8 & 0.2 & 0.4 & 2.0 & 0.1 & 0.8 \\
\hline
\end{tabular}

${ }^{\mathrm{z} F r u i t}$ index: fruit length/fruit width.

Summer fruits were harvested in July 2004 and winter fruits in Mar. 2005.

TSS $=$ total soluble solids; LSD $=$ least significant difference.

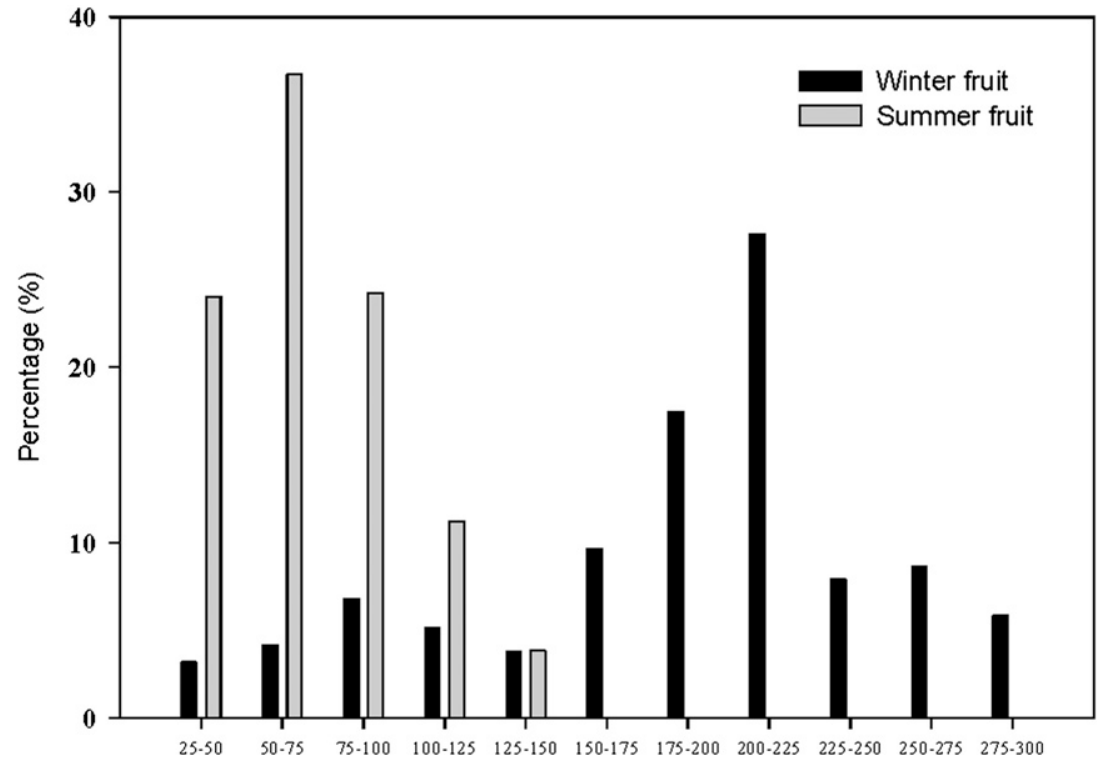

Fruit weight $(\mathrm{g})$

Fig. 6. Weight of yellow pitaya summer and winter fruits under conditions of no fruit thinning and artificial pollination. Summer fruits were harvested in July 2004 and winter fruits in Mar. 2005. The sums of the percentages of each category for either summer or winter fruits were $100 \%$.

emerged before July was from noncurrent shoots and that emerged after July was from current shoots (Fig. 3). Because the fall flowering wave relies heavily on current shoots, proper management for canopy composition should be very important if we aim at increasing winter fruit yield.
In yellow pitaya, major sprouting occurred in the winter and spring in Taiwan (Fig. 2). Only $0.2 \%$ to $2.5 \%$ of areoles transformed into floral buds (Table 2), a figure similar to Hylocereus sp. (Hsu, 2004). The remaining areoles of the shoot may retain their ability to flower for several seasons. The ratio of current shoots transformed into flowering shoots increased as the number of areoles on the shoots increased (Table 2). Because fall flowering depends on current shoots (Fig. 3), raising current shoots to have more areoles (e.g., more than 60) may enhance fall flowering. Thus, removing excessive shoots, adequate nutritional supplement, and adequate irrigation in the sprouting period would be advisable.

Nerd and Mizrahi (1998) proposed that temperature affects the rate of fruit development in yellow pitaya. In Taiwan, we observed that 10 weeks were required from flowering to fruit harvest for the summer crop, and 18 weeks were needed for the winter crop (data not shown). TSS varied depending on the parts of the fruit examined (Fig. 8). The TSS distribution pattern in each fruit was similar to that of H. undatus (Chang and Yen, 1997). This pattern may be related to invertase and amylase activity in different parts of the fruit (Wu and Chen, 1997).

Under open-pollinated and non-fruit thinning conditions, we observed that the quality of winter fruit was superior to that of summer fruit (Table 3). Furthermore, only $4 \%$ of the summer fruits weighed more than $125 \mathrm{~g}$, whereas $80 \%$ of the winter fruits weighed more than $125 \mathrm{~g}$ (Fig. 6). A fruit weight of $110 \mathrm{~g}$ or greater is considered to be the marketable weight threshold in Taiwan. Although the open-pollinated summer fruits were small, the early-season availability and the abundant fruiting are marketing benefits. Because the fruit size highly depends on the competition of carbohydrate resources, thinning flowers and young fruits may increase the percentage of marketable fruits (Inglese et al., 1995; Zegbe and Mena-Covarrubias, 2009).

The pulp of the cactus fruit is derived from the funicular envelopes and papillae (Maheshwari and Chopra, 1955; Nerd and Mizrahi, 1997). Previous studies reported that the number of seeds positively correlated with fruit weight in Hylocereus sp. (Hsu, 2004; Weiss et al., 1994), S. megalanthus (Weiss et al., 1994), and O. ficus-indica (Barbera et al., 1994). We found that the number of black seeds in yellow pitaya had the highest positive correlation with pulp weight $\left(R^{2}=\right.$ 0.87 ) among all sorts of seeds (Fig. 7). In summer fruits, $58 \%$ of seeds were either brown or vestigial and were aborted and only $42 \%$ were black and viable. The number of black seeds in winter fruits was two- to threefold higher than that in summer fruits (data not shown). A higher number of black seeds might contribute to larger fruits in the winter crops. Dag and Mizrahi (2005) increased the fruit size of yellow pitaya by hand pollination. Thus, artificial pollination may be useful in Taiwan as well.

The pitaya industry has expanded in the past decade, and stabilizing winter production is a high priority. Although the yellow pitaya flowering phenology overlaps that of the currently popular varieties in the Hylocereus genus, yellow pitaya has the potential to yield winter fruits of superior quality. Because noncurrent shoots mainly flower in late spring and current shoots flower in fall, managing the 


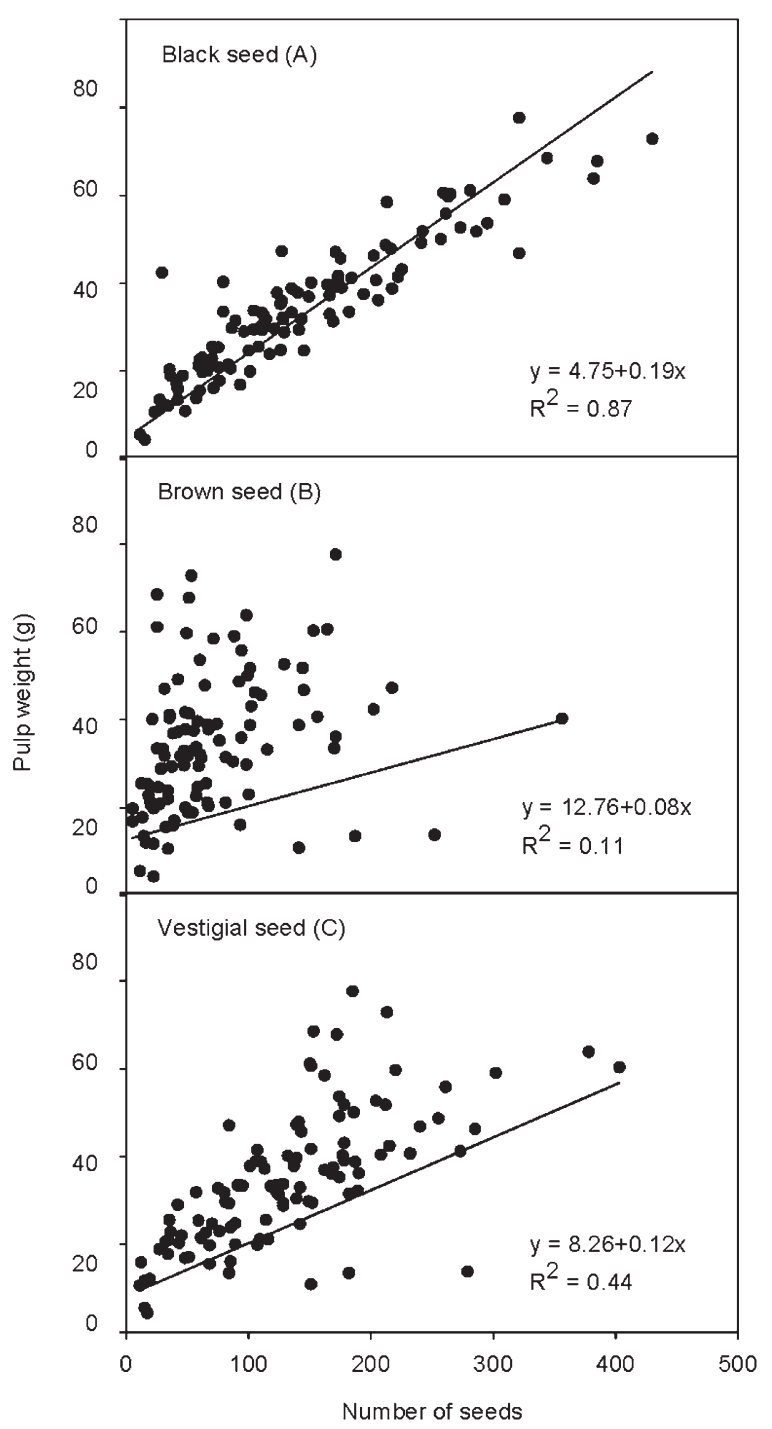

Fig. 7. Relationship of pulp weight and number of seeds in S. megalanthus $(\mathrm{n}=105)$. Fruits were harvested in July 2004.

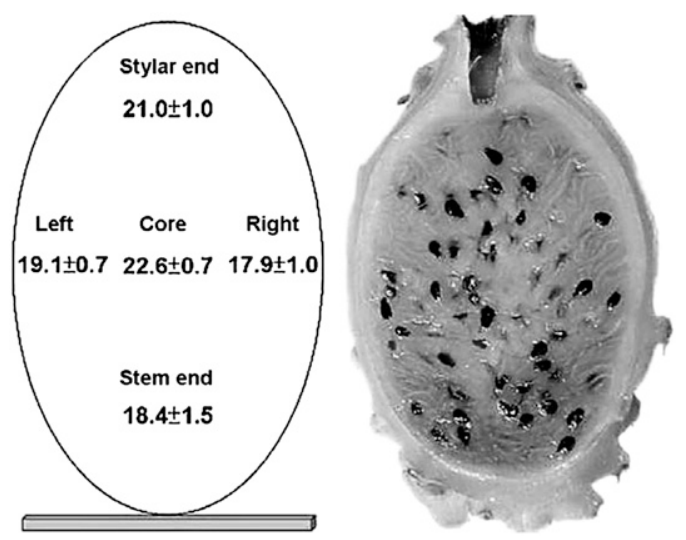

Fig. 8. Total soluble solids of different parts of the pulp of winter fruits (harvested in Mar. 2005) of yellow pitaya. The average fruit weight was $202.6 \pm 32.0 \mathrm{~g}$. Data are presented as means $\pm \mathrm{SE}(\mathrm{n}=15)$

current shoots to have more than 60 areoles per shoot would be an important way leading to winter fruit production. Delaying the flowering of noncurrent shoots to fall by flower thinning or $\mathrm{GA}_{3}$ application may be another approach (Khaimov and Mizrahi, 2006). On the other hand, controlling fruit load per shoots by thinning flowers and young fruits on noncurrent shoots may result in increasing summer fruits of marketable size. In addition, the effect of artificial pollination on increasing fruit size should be evaluated further.

\section{Literature Cited}

Anderson, E.F. 2001. The cactus family. Timber Press, Portland, OR.

Barbera, G., F. Carimi, and P. Inglese. 1991a. Past and present role of the Indian-fig prickly-pear [Opuntia ficus-indica (L.) Miller, Cactaceae] in the agriculture of Sicily. Econ. Bot. 46:10-20.

Barbera, G., F. Carimi, and P. Inglese. 1991b. The reflowering of prickly pear Opuntia ficus-indica (L.) Miller: Influence of removal time and cladode load on yield and fruit ripening. Adv. Hort. Sci. 2:77-80.

Barbera, G., P. Inglese, and T. La Mantia. 1994. Seed content and fruit characteristics in cactus pear (Opuntia ficus-indica Mill.). Sci. Hort. 58:161-165.

Chang, F.R. and C.R. Yen. 1997. Flowering and fruit growth of pitaya (Hylocereus undatus Britt \& Rose). J. Chinese Soc. Hort. Sci. 43: 314-321.

Dag, A. and Y. Mizrahi. 2005. Effect of pollination methods on fruit set and fruit characteristics of the vine cactus Selenicereus megalanthus ('yellow pitaya'). J. Hortic. Sci. Biotechnol. 80:618-622.

Hsu, W.T. 2004. Investigations on culture, growth habits and phenology in pitaya (Hylocereus spp.). MS thesis, Natl. Taiwan Univ., Taiwan.

Inglese, P., G. Barbera, and F. Carimi. 1994. The effect of different amounts of shoot removal on reflowering of cactus pear [Opuntia ficus-indica (L.) Miller]. J. Hort. Sci. 69:61-65.

Inglese, P., G. Barbera, T. La Mantia, and S. Portolano. 1995. Crop production, growth and ultimate size of cactus pear fruits following fruit thinning. HortScience 30:227-230.

Jiang, Y.L. 2005. Classification, flowering and fruiting characteristics, and pruning of climbing cactus. MS thesis, Natl. Taiwan Univ., Taiwan.

Khaimov, A. and Y. Mizrahi. 2006. Effects of daylength, radiation, flower thinning and growth regulators on flowering of the vine cacti Hylocereus undatus and Selenicereus megalanthus. J. Hort. Sci. Biotechnol. 81:465-470.

Lichtenzveig, J., S. Abbo, A. Nerd, N. Tel-Zur, and Y. Mizrahi. 2000. Cytology and mating system in the climbing cacti Hylocereus and Selenicereus. Amer. J. Bot. 87:1058-1065.

Maheshwari, P. and R.N. Chopra. 1955. The structure and development of the ovule and seed of Opuntia dillenii Haw. Phytomorphology 5:112-122.

Mizrahi, Y. and A. Nerd. 1996. New crops as a possible solution for the trouble Israeli export market, p. 37-45. In: Janick, J. (ed.). Progress in new crops. ASHS Press, Alexandria, VA.

Mizrahi, Y. and A. Nerd. 1999. Climbing and columnar cacti: New arid land fruit crops, p. 358-366. In: Janick, J. (ed.). Perspectives on new crops and new uses. ASHS, Alexandria, VA.

Mizrahi, Y., A. Nerd, and P.S. Nobel. 1997. Cacti as crops. Hort. Rev. 18:291-391.

Mizrahi, Y., A. Nerd, and Y. Sitrit. 2002. New fruit for arid climates, p. 378-384. In: Janick, J. (ed.). Trends in new crops and new uses. ASHS, Alexandria, VA.

Nerd, A. and Y. Mizrahi. 1997. Reproductive biology of fruit cacti. Hort. Rev. 18:322-346.

Nerd, A. and Y. Mizrahi. 1998. Fruit development and ripening in yellow pitaya. J. Amer. Soc. Hort. Sci. 123:560-562.

Nerd, A., Y. Sitrit, R.A. Kaushik, and Y. Mizrahi. 2002a. High summer temperatures inhibit 
flowering in vine pitaya crops (Hylocereus spp.). Scientia Hort. 96:343-350.

Nerd, A., N. Tel-Zur, and Y. Mizrahi. 2002b. Fruits of vine and columnar cacti, p. 185-197. In: Nobel, P.S. (ed.). Cacti biology and uses. Univ. California Press, London, UK.

Nieddu, G. and D. Spano. 1992. Flowering and fruit growth in Opuntia ficus-indica. Acta Hort. 296:153-159.

Raveh, E., A. Nerd, and Y. Mizrahi. 1998. Responses of two hemiepiphytic fruit crop cacti to different degrees of shade. Sci. Hort. 73:151-164.

Raveh, E., J. Weiss, A. Nerd, and Y. Mizrahi. 1993. Pitayas (genus Hylocereus): A new fruit crop for the Negev desert of Israel, p. 491-495. In: Janick, J. and J.E. Simon (eds.). New crops. Wiley, New York, NY.

Tel-Zur, N., S. Abbo, D. Bar-Zvi, and Y. Mizrahi. 2004. Genetic relationships among Hylocereus and Selenicereus vine cacti (Cactaceae): Evidence from hybridization and cytological studies. Ann. Bot. (Lond.) 94:527-534.

Weiss, J., A. Nerd, and Y. Mizrahi. 1994. Flowering behavior and pollination requirements in climbing cacti with fruit crop potential. HortScience 29:1487-1492.

Weiss, J., L. Scheinvar, and Y. Mizrahi. 1995. Selenicereus megalanthus (the yellow pitaya) a climbing cactus from Colombia and Peru. Cactus and Succulent J. 67:280-283.

Wu, M.C. and C.S. Chen. 1997. Variation of sugar content in various parts of pitaya fruit. Proc. Fla. State. Hort. Soc. 110:225-227.

Yen, C.R. and F.R. Chang. 1997. Forcing pitaya (Hylocereus undatus Britt. \& Rose) by chemicals, controlled day length and temperature. Proc. Symp. Enhancing Competitiveness of Fruit Ind., Taichung District Agricultural Improvement Station. Taiwan. 3:163-170.

Zegbe, J.A. and J. Mena-Covarrubias. 2009. Flower bud thinning in 'Rojo Liso' cactus pear. J. Hort. Sci. Biotechnol. 84:595-598. 